governance meeting featured a case: the young patient died. Please also note its use as a remedy for 'pericarditis' is not currently supported by the British National Formulary.

\section{Bullying and banter}

I couldn't help noticing the possibly unfortunate juxtaposition of these two editorials in your latest issue. While accepting that both childhood bullying and derogatory banter regarding general practice and psychiatry (the latter having existed for generations) are unacceptable, I can only guess the response from some of the more 'aggressive' secondary care specialties to these concurrent calls to right wrongs. In either circumstance, only strength from the aggrieved will be respected: victimhood will not win the day!

In respect of childhood bullying, any GP will of course respond appropriately to patient distress, but to make an expectation of GPs on this subject broadens their remit, yet further increases demands on them, and sets them up to fail; not what is needed in the current environment of low morale.

In respect of our secondary care colleagues' 'banter', an invitation to spend 2-3 days of annual study leave shadowing a GP trainer in their practice should do the trick! A consultant gynaecological oncologist advised me some years ago that he was in awe of how GPs manage such diversity of demand. A specialist can, with justification, claim professional ignorance outside their speciality; a GP has no such luxury!

Vernon Needham,

Retired GP, Andover.

E-mail: vernonneedhamanhs.net

\section{REFERENCES}

1. Scott EJ, Dale J. Childhood bullying: implications for general practice. Br J Gen Pract 2016; DOI: 10.3399/ bjgp16X687145. http://bjgp.org/content/66/651/504.

2. Baker M, Wessely S, Openshaw D. Not such friendly banter? GPs and psychiatrists against the systematic denigration of their specialties. Br J Gen Pract 2016; DOI: 10.3399/bjgp16X687169. http://bjgp.org/ content/66/651/508.

DOI: 10.3399/bjgp16X688093

\section{Colchicine in overdose}

Would colleagues please be aware of the devastating consequences of a significant colchicine overdose, particularly when prescribing for patients with previous history of low mood. It is deadly; there is no antidote. Our recent emergency department

\section{Gavin Lloyd,}

Consultant Emergency Physician and ED Patient Champion, Royal Devon \& Exeter NHS Foundation Trust

E-mail: gavin.lloydlanhs.net

\section{REFERENCE}

1. Sinnige J, Korevaar JC, van Lieshout J, et al. Medication management strategy for older people with polypharmacy in general practice: a qualitative study on prescribing behaviour in primary care. $\mathrm{Br} \mathrm{J}$ Gen Pract 2016; DOI: 10.3399/bjgp16X685681. http:// bjgp.org/content/66/649/e540.

\section{DOI: 10.3399/bjgp16X688333}

\section{Child health training and the College}

Although it is not in the College's gift to remove approval from training programmes, we do share the concerns expressed by Dr Sharvill in his letter. ${ }^{1}$ The College is aware that general practice training is not long enough and that it is difficult to fit all of the necessary training experiences and placements into a 3 -year envelope. The time spent in general practice has been extended from 12 to 18 months, which provides trainees with a greater opportunity to experience a full range of different clinical specialisms within the general practice context. We also regularly review our curriculum, and have enhanced child health in the MRCGP assessments.

In addition, we have published a joint position statement with the Royal College of Paediatrics and Child Health entitled Learning Together to Improve Child Health, which advocates the importance of interprofessional training. ${ }^{2}$ We are also undertaking a joint survey of the number of training placements in paediatrics to better understand the scale of the problem and how it might best be addressed.

This is an issue of great importance to the College and we want to ensure that all GP trainees have access to the paediatric and child health training and experience that they need to be both competent and confident in this important area.

\section{Kamila Hawthorne,}

Vice Chair (Professional Development), Royal College of General Practitioners.

\section{E-mail: kamila.hawthornedrcgp.org.uk}

\section{REFERENCES}

1. Sharvill NJ. Child health training: why does the College not act? [Letter]. Br J Gen Pract 2016: DOI: 10.3399/bjgp16X685801. http://bjgp.org/ content/66/648/350.1

2. Royal College of General Practitioners, Royal College of Paediatrics and Child Health. Learning together to improve child health. London: RCPCH, 2016. www.rcpch.ac.uk/news/learning-togetherimprove-child-health (accessed 7 Nov 2016).

DOI: 10.3399/bjgp16X688105

\section{Cruse Bereavement Care}

I read with interest McDonnelland colleagues article about dealing with parents bereaved by suicide, ${ }^{1}$ and Hamilton's article in the same issue. ${ }^{2}$ I wonder why GPs do not make better use of Cruse? Cruse Bereavement Care is a national charity that offers help to anyone who has been bereaved, including 'complicated bereavements' and 'complicated grief', such as by suicide or sudden traumatic death. The bereavement volunteers undergo intensive initial selection and training, and continue to have ongoing training and supervision, to a highly professional level. They can offer help to clients either one-to-one or in groups. The clients' evaluations show that they feel their mental and physical health improve as a result of this contact. Clients refer themselves, but are often advised by their GPs to do so: in our area half say they have been advised by their GP to contact us.

With the difficulties GPs are experiencing with such pressure on their time, and also the lack of confidence in dealing with these issues, it would seem logical for CCGs to be working with Cruse to provide the service the bereaved deserve and need.

\section{Mary Davis,}

Retired GP, Godalming; Chair, Southwest Surrey Cruse Bereavement Care.

E-mail: drmaryeldlaaol.com

\section{REFERENCES}

1. Foggin $E$, McDonnell S, Cordingley L, et al. GPs experiences of dealing with parents bereaved by suicide: a qualitative study. Br J Gen Pract 2016; DOI: 10.3399/bjgp16X686605. http://bjgp.org/ content/66/651/e737.

2. Hamilton IJ. Understanding grief and bereavement Br J Gen Pract 2016; DOI: 10.3399/bjgp16X687325. http://bjgp.org/content/66/651/523.

DOI: 10.3399/bjgp16X688117 